\title{
Influence of lightweight aggregate on the bond properties of concrete with various strength grades
}

\author{
Kim Hung Mo ${ }^{\mathrm{a}, *}$, U. Johnson Alengaram ${ }^{\mathrm{a}, *}$, Phillip Visintin ${ }^{\mathrm{b}}$, See Heng Goh ${ }^{\mathrm{a}}$, Mohd Zamin Jumaat ${ }^{\mathrm{a}}$ \\ a Department of Civil Engineering, Faculty of Engineering, University of Malaya, 50603 Kuala Lumpur, Malaysia
}

${ }^{\mathrm{b}}$ School of Civil, Environmental and Mining Engineering, University of Adelaide, South Australia 5005, Australia

H I G H L I G H T S

- Higher bond strength of OPSC compared to NWC with similar compressive strength.

- OPSC and NWC exhibit similar shape of bond stress-slip curves.

- Proposed bond models for OPSC and NWC gave good match to experimental values.

- Determination of prediction equation for mechanical properties and shrinkage of OPSC.

A R T I C L E I N F O

\section{Article history:}

Received 21 September 2014

Received in revised form 16 February 2015

Accepted 4 March 2015

Available online 27 March 2015

\section{Keywords:}

Lightweight aggregate

Bond strength

Bond model

Mechanical properties

Drying shrinkage

Oil palm shell

\section{A B S T R A C T}

This paper presents the comparison of the bond and mechanical properties of lightweight oil palm shell concrete (OPSC) and normal weight concrete (NWC) with three different strength grades of 25, 35 and $45 \mathrm{MPa}$. Although the mechanical properties such as splitting tensile strength and modulus of elasticity as well as the performance of drying shrinkage of OPSC were found to be inferior compared to NWC, the bond strength of OPSC was found to be up to $80 \%$ higher compared to the corresponding NWC of equivalent cube compressive strength grade. Results also showed that the shape of the bond stress-slip curve for OPSC was similar to conventional NWC. In addition, in this paper, modified bond models based on the CEB-FIP bond model was proposed for both OPSC and NWC which were found to give good prediction of the experimental bond stress-slip curve of the concretes.

(c) 2015 Elsevier Ltd. All rights reserved.

\section{Introduction}

A recent development in the manufacture of lightweight concrete (LWC) is the utilization of oil palm shell (OPS) as lightweight aggregate. OPS is an agriculture waste material resulting from the extraction of palm oil and are widely available in countries with vast oil palm plantation, particularly in the South East Asia region. In the past, studies on the production of lightweight OPS concrete (OPSC) [1-3] as well as the cement-less geopolymer OPSC [4] have been carried out with the aim of producing a more environmental friendly concrete. These works have mainly focused on obtaining basic mechanical properties [5] as well as preliminary studies to define bond capacities [6,7].

The bond between concrete and reinforcing bar is an important property in reinforced concrete member since it is responsible for

\footnotetext{
* Corresponding authors. Tel.: +60 379677632; fax: +60 379675318.

E-mail addresses: khm0890815@gmail.com (K.H. Mo), johnson@um.edu.my (U.J. Alengaram).
}

transfer of axial force between these two materials. Insufficient bond strength could lead to loss of strain compatibility and excessive slip which could result in permanent deformation of reinforced concrete structures. The adequate knowledge of the bond properties is also required to determine the development length to prevent premature bond failure of reinforced concrete members. The lack of available information relating to development lengths in LWC is evidenced by the incorporation of an additional safety factor for LWC in ACl-318 [8]. The magnitude of this additional safety factor is however debatable as there are inconclusive reports on the bond strength of LWC. For instance, Lyse [9] and Shideler [10] reported that the bond strength of LWC made with slag and expanded shale aggregate were comparable to NWC, while Lachemi et al. [11] found lower bond strength of lightweight self-compacting concrete (SCC) containing both of these lightweight aggregates compared to normal weight SCC. Several other investigations have also reported inferior bond strength of LWC made with lightweight aggregates such as pumice [12] and tuff [13] compared to NWC. On the contrary, Clarke and Birjandi [14] 
found higher bond strength for LWC containing expanded clay, sintered pulverized fuel ash and pelletized expanded blast furnace slag aggregates. Maree and Riad [15] also reported higher bond strength of foamed LWC compared to NWC.

In addition, the local bond properties can be utilized in numerical model to simulate the tension stiffening behaviour such as in the well-established mechanics of partial interaction analysis [16] to predict short term deflections of structural members [17]. Furthermore, the knowledge of the local bond properties allows for the determination of the crack spacing and crack width of structural members through the use of a mechanics-based moment-rotation approach for member analysis [17].

The lack of information on the bond behaviour of lightweight OPSC has enthused research interest to carry out this investigation of the bond characteristics of OPSC. OPSC and NWC with similar targeted cube compressive strengths of 25,35 and $45 \mathrm{MPa}$ were tested to facilitate the comparison of their bond behaviours. In addition, this paper also deals with the effect of the aggregates, namely OPS and conventional crushed granite used in LWC and NWC, respectively on the mechanical properties and drying shrinkage behaviour of concrete. The knowledge of the mechanical properties of OPSC such as tensile strength and modulus of elasticity (MoE) is essential since as they are interrelated with the bond properties and are generally required in structural analysis while the shrinkage strain could also be applied in the partial interaction analysis [16] to predict changes in the tension stiffening behaviour over time and hence long term deflections of structural members [18]. It should be noted, however, that the analysis of member behaviour is not the purpose of this paper but rather the study of the material properties for future use in numerical model.

\section{Materials and mix proportions}

The uncrushed OPS (Fig. 1) with sizes between 2.36 and $14 \mathrm{~mm}$ and bulk density of $587 \mathrm{~kg} / \mathrm{m}^{3}$ were used in the manufacture of OPSC. The specific gravity and $24 \mathrm{~h}$ water absorption of the OPS were respectively 1.34 and $26 \%$. The OPS was pre-soaked for $24 \mathrm{~h}$ and used in saturated surface dry (SSD) condition. In the manufacture of NWC, crushed granite coarse aggregate of sizes between 5 and $14 \mathrm{~mm}$ facture of NWC, crushed granite coarse aggregate of sizes between 5 and $14 \mathrm{~mm}$
and with a specific gravity of 2.65 was used. The gradation curves of OPS and and with a specific gravity
granite are shown in Fig. 2.

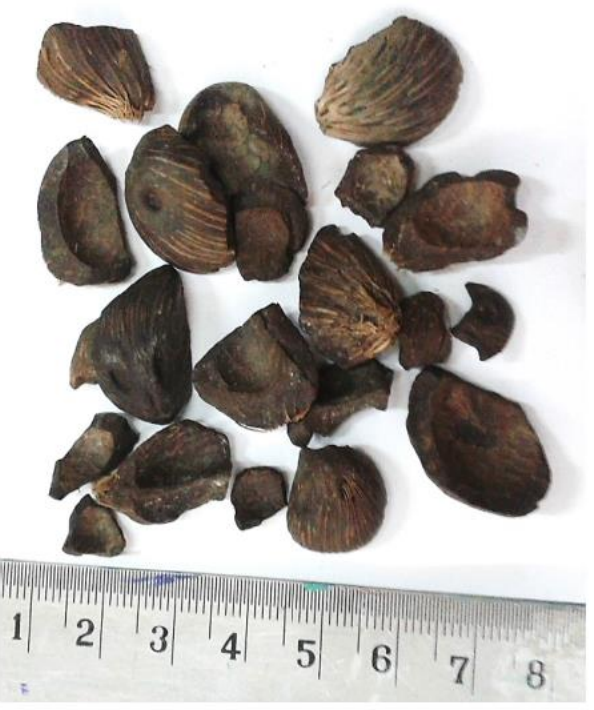

Fig. 1. OPS as lightweight coarse aggregate.

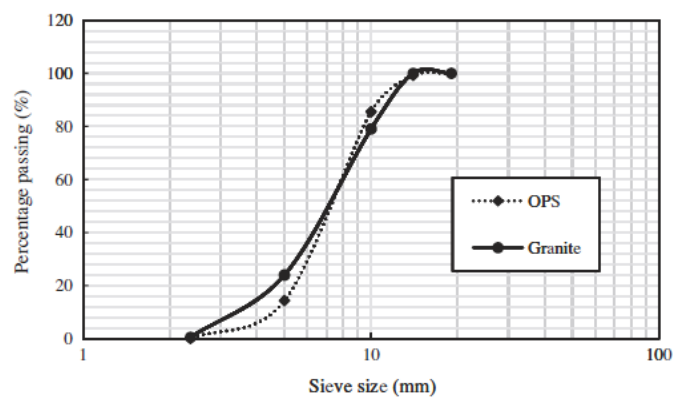

Fig. 2. Gradation curve of OPS and granite.

Table 1

Mix proportions for OPSC and NWC

\begin{tabular}{llrrrll} 
Mix & \multicolumn{6}{l}{ Mix proportions $\left(\mathrm{kg} / \mathrm{m}^{3}\right)$} \\
\cline { 2 - 7 } & Cement & OPS & Granite & Sand & Water & SP \\
\hline L1 & 470 & 425 & 0 & 850 & 200 & - \\
L2 & 515 & 410 & 0 & 950 & 160 & 5.2 \\
L3 & 560 & 365 & 0 & 960 & 175 & 5.6 \\
N1 & 295 & 0 & 855 & 975 & 205 & - \\
N2 & 320 & 0 & 810 & 1030 & 200 & - \\
N3 & 350 & 0 & 1345 & 535 & 175 & - \\
\hline
\end{tabular}

Mining sand with specific gravity of 2.73 passing through $5 \mathrm{~mm}$ sieve was used s fine aggregates for all the mixes.

Ordinary Portland cement (OPC) with specific gravity and surface area of 3.10 and $352 \mathrm{~m}^{2} / \mathrm{kg}$, respectively, was used. Potable water that was free from contaminant and impurities was used as the mixing water in all the mixes.

Concrete strength grades of 25,35 and 45 for both OPSC and NWC were targeted and trial mixes were carried out beforehand to ensure the targeted strength could be achieved. Mix proportions for all OPSC and NWC grades are presented in The 1 where the mixes Table 1, where the mixes with designations ' $L$ ' and ' $N$ ' denote $O{ }^{\prime}$ ' respectively; furthermore the numberings ' 1,2 ' and ' 3 ' denote targeted concrete strength grade of 25,35 and 45 , respectively. Polycarboxylate-ether based superplasticizer (SP) was used at $1.0 \%$ by the mass of cement for mixes L2 and L3 to ensure sufficient workability.

In the mixing process, coarse aggregates and sand were initially dry mixed for $3 \mathrm{~min}$ and this was followed by the addition of cement and a further mixing was done for another $3 \mathrm{~min}$. And with the addition of water, wet mixing was carried out for a further $6 \mathrm{~min}$. After the mixing was completed, the concrete was poured into oiled moulds and compacte All the specimens were de-moulded after 24

\section{Test methods}

\subsection{Mechanical properties}

The compressive strength (BS EN 12390-3: 2002), splitting tensile strength (BS EN 12390-6: 2000) and modulus of elasticity (ASTM C469-10) tests were carried out at the age of 28 days on specimens of $100 \mathrm{~mm}$ cube, $100 \mathrm{~mm} \phi \times 200 \mathrm{~mm}$ height cylinder and $150 \mathrm{~mm} \phi \times 300 \mathrm{~mm}$ height cylinder, respectively. A total of three specimens were tested for each mix and the average of the three values was reported.

\subsection{Drying shrinkage}

After de-moulding of specimens, demountable mechanical (DEMEC) gauge studs were attached to prism specimens of dimension $75 \times 75 \times 300 \mathrm{~mm}$. The specimens were then kept in a room in which the temperature and humidity were maintained at $20 \pm 2{ }^{\circ} \mathrm{C}$ and $60 \pm 5 \%$, respectively. Observations on the initial position of DEMEC studs were taken using a length comparator (Fig. 3). 


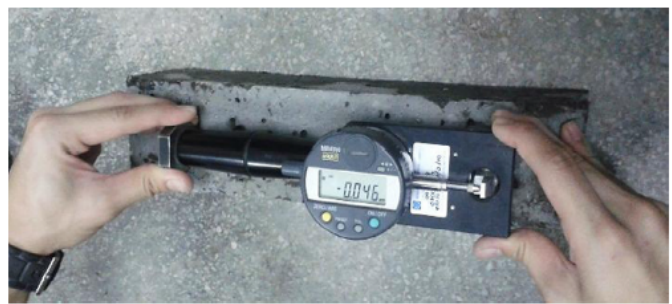

Fig. 3. Drying shrinkage test.

The changes in length of the specimens thereafter were measured at regular intervals up to 150 days for the determination of the drying shrinkage.

\subsection{Bond}

Bond behaviour was investigated using direct pull-out tests on specimens as shown in Fig. 4. The reinforcing bar was embedded concentrically in the concrete prism of cross section $200 \times 200 \mathrm{~mm}$ and $350 \mathrm{~mm}$ height. The dimensions were chosen to ensure splitting failure did not occur.

For all tests high yield ribbed steel reinforcing bars of $12 \mathrm{~mm} \phi$ with a yield strength of $500 \mathrm{MPa}$ were used. The distance between the ribs of the steel reinforcing bar was measured and it was found as $6.4 \mathrm{~mm}$. The bonded length of the reinforcing bar of $3.5 \phi$ $(42 \mathrm{~mm})$ was maintained at mid-height of the prism to ensure a uniform distribution of slip over the bonded length without yielding of the reinforcing bar. The remainder of bar was enclosed using a PVC tube to act as a bond breaker and a layer of sponge was placed between the reinforcing bar and the PVC tube.

The bond test was carried out at the age of 28-day. During testing, the free un-bonded length of the reinforcing bar was gripped and subjected to concentric tension pull-out load via a Universal Testing Machine at a rate of $1 \mathrm{~mm} / \mathrm{min}$. The slip of the steel reinforcing bar relative to the concrete was measured through the use of four linear variable displacement transducers (LVDT). The average readings from the four LVDT were taken as the value of the slip. The pull-out load and the readings from the LVDT were recorded continuously at $1 \mathrm{~s}$ interval using a data logger.

\section{Results and discussion}

\subsection{Density}

According to the oven dry densities shown in Table 2, the OPSC produced in the study could be classified as LWC in accordance to the classification in EN 206-1 [19]. The 28-day SSD density of OPSC and NWC are also shown in Table 2. It should be noted that the difference between the SSD and oven dry density of OPSC ranged between 150 and $180 \mathrm{~kg} / \mathrm{m}^{3}$. As expected, for both OPSC and NWC, the observed SSD density was higher for concrete with higher concrete strength grade. Importantly, it is shown in Table 2 that the use of OPS as lightweight aggregate reduces the density of concrete by about $20 \%$ irrespective of the strength. Furthermore, when comparing the material efficiency of concrete, OPSC generally exhibited stronger performance than that of NWC as demonstrated by the higher compressive strength to density ratio of OPSC (Table 2).

\subsection{Mechanical properties}

4.2.1. Compressive strength

Cube and cylinder compressive strengths of both OPSC and NWC are presented in Table 2. All the mixes achieved the targeted cube compressive strength with the deviations of up to $7 \%$. The cylinder to cube compressive strength ratio of OPSC was found to be in the range of $0.62-0.69$ whereas the ratio was slightly higher for NWC in the range of $0.75-0.77$. The lower cylinder to cube compressive strength ratio for OPSC could be due to its lower modulus of elasticity (MoE) compared to NWC [7] which could result in higher restraining effect of testing machine platens. As known, the cube specimens are then subjected to tri-axial stress unlike uni-axial stress on cylinder specimens (height to diameter ratio of 2) and thus resulting in higher measured compressive strength for the cube specimens [20].

4.2.2. Modulus of elasticity ( $M o E)$

As shown in Table 3, the MoE values obtained from this study was found in the range of 9-15 GPa and this is in agreement with the previously reported values for OPSC $[7,21,22]$ whereas in the case of NWC, the MoE generally ranged between 30-37 GPa. Therefore, the MoE of OPSC were about $30-40 \%$ of that for NWC due to lower stiffness of OPS compared to granite aggregate as reported by Alengaram et al. [7]. Besides that, as expected, higher compressive strength resulted in higher MoE of concrete in both

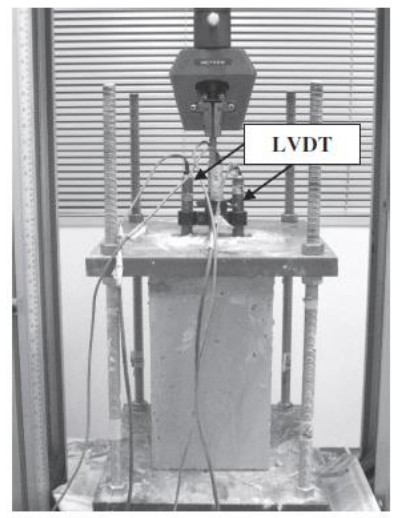

Fig. 4. Bond test specimen 
Table 2

28-Day density and compressive strength of OPSC and NWC.

\begin{tabular}{lllllll}
\hline Mix & $\begin{array}{l}\text { SSD density } \\
\left(\mathrm{kg} / \mathrm{m}^{3}\right)\end{array}$ & $\begin{array}{l}\text { Oven dry density } \\
\left(\mathrm{kg} / \mathrm{m}^{3}\right)\end{array}$ & $\begin{array}{l}\text { Cube compressive } \\
\text { strength }(\mathrm{MPa}) \\
(\mathrm{b})\end{array}$ & $\begin{array}{l}\text { Cylinder compressive } \\
\text { strength }(\mathrm{MPa}) \\
(\mathrm{c})\end{array}$ & $\begin{array}{l}\text { Strength to density } \\
\text { ratio } \\
(\mathrm{b}) /(\mathrm{a})\end{array}$ & $\begin{array}{l}\text { Cylinder to cube } \\
\text { strength ratio } \\
(\mathrm{c}) /(\mathrm{b})\end{array}$ \\
\hline L1 & 1960 & 1800 & 25.3 & 16.8 & 0.0129 & 0.0171 \\
L2 & 2060 & 1880 & 35.2 & 21.7 & 0.0218 & 0.62 \\
L3 & 2110 & 1960 & 46.0 & 31.8 & 0.0110 & 0.69 \\
N1 & 2430 & - & 26.8 & 20.2 & 0.0145 & 0.75 \\
N2 & 2460 & - & 35.7 & 27.7 & 0.0166 \\
N3 & 2550 & - & 42.4 & 32.8 & 0.76 \\
\hline
\end{tabular}

Table 3

28-Day mechanical properties of OPSC and NWC.

\begin{tabular}{lllll}
\hline Mix & $\begin{array}{l}\text { Cube } \\
\text { compressive } \\
\text { strength } \\
\text { (MPa) }\end{array}$ & $\begin{array}{l}\text { Modulus of } \\
\text { elasticity } \\
\text { (GPa) }\end{array}$ & $\begin{array}{l}\text { Splitting } \\
\text { tensile } \\
\text { strength } \\
\text { (MPa) }\end{array}$ & $\begin{array}{l}\text { Ratio of splitting tensile } \\
\text { to cube compressive } \\
\text { strength }\end{array}$ \\
\hline L1 & 25.3 & 8.9 & 2.59 & 0.102 \\
L2 & 35.2 & 10.7 & 2.75 & 0.078 \\
L3 & 46.0 & 15.5 & 3.55 & 0.077 \\
N1 & 26.8 & 30.1 & 2.71 & 0.101 \\
N2 & 35.7 & 35.0 & 3.05 & 0.085 \\
N3 & 42.4 & 37.0 & 3.53 & 0.083 \\
\hline
\end{tabular}

OPSC and NWC as a result of increased cement content as well as the reduced water/cement $(\mathrm{w} / \mathrm{c})$ ratio for mixes with higher targeted compressive strength. Both of these factors could lead to improved microstructure of concrete and increased MoE values.

The relationship between the compressive strength and the MoE of OPSC could be related using Eq. (1) as proposed by Alengaram et al. [23] since the experimental values agreed fairly well with the predicted MoE values as shown in Fig. 5. Besides that, as mentioned in Section 4.2.1, one of the reasons affecting the ratio of the cylinder to cube compressive strength of the OPSC and NWC could be due to the $\mathrm{MoE}$ values of the concrete. A direct relationship is therefore proposed to relate the MoE values with the ratio of the cylinder to cube compressive strength of concrete. As shown in Fig. 6, a good correlation existed for this relationship and hence Eq. (2) is proposed to predict the ratio of cylinder to cube compressive strength.

$E_{\mathrm{s}}=(\rho / 2400)^{2} \times\left(f_{\mathrm{cu}}\right)^{1 / 3} \times 5.0$

where $E_{\mathrm{s}}$ is the $\mathrm{MoE}(\mathrm{GPa}), \rho$ is the density $\left(\mathrm{kg} / \mathrm{m}^{3}\right)$ and $f_{\mathrm{cu}}$ is the cube compressive strength (MPa) of OPSC.

$R=0.005 E_{\mathrm{s}}+0.5985\left(R^{2}=0.909\right)$

where $R$ is the ratio of the cylinder to cube compressive strength.

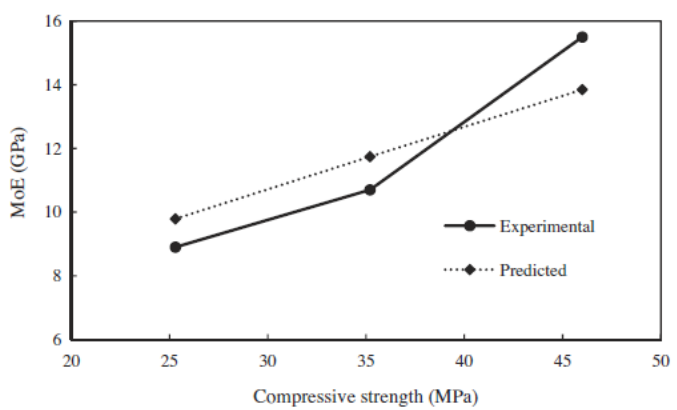

Fig. 5. Experimental and predicted MoE values of OPSC with different strength grade.

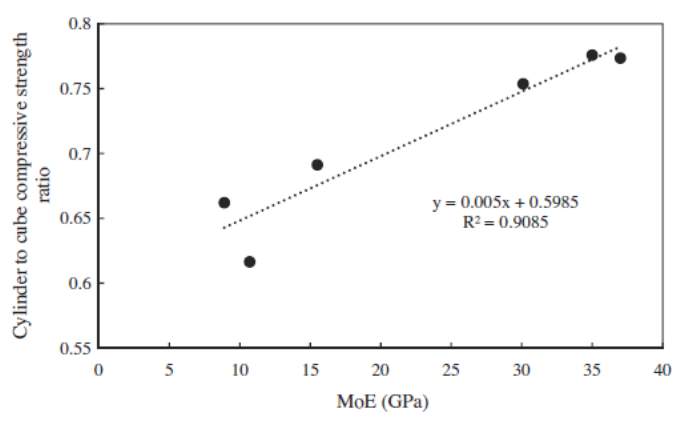

Fig. 6. Relationship between MoE and cylinder to cube compressive strength ratio.

\subsubsection{Splitting tensile strength}

A comparison between the splitting tensile strengths of OPSC and NWC is shown in Table 3 where it can be seen that the splitting tensile of OPSC is between $8 \%$ and $10 \%$ of the compressive strength. Generally, OPSC exhibited inferior splitting tensile strength compared to NWC, except for the grade 25. Alengaram et al. [7] opined that the weaker bond between the interface of OPS and the cement matrix caused the lower splitting tensile strength of OPSC. The lower splitting tensile strength of OPSC could also be attributed to the lower strength of OPS aggregate compared to conventional granite aggregate. Another reason which contributed to the lower tensile strength of OPSC could be the lower stiffness of OPS aggregate compared to conventional granite aggregate. In addition, the concrete mixes of OPSC require higher quality of cement paste through the use of relatively higher cement content coupled with lower $\mathrm{w} / \mathrm{c}$ ratio compared to NWC of similar strength grade. Consequently, the MoE of the cement paste in the OPSC could be higher than that for NWC; thus combining the effects of lower stiffness of OPS aggregate and higher MoE of cement paste in OPSC, the higher difference in $\mathrm{MoE}$ between the aggregate and cement matrix for OPSC compared to NWC could cause early cracking of the OPSC when subjected to tensile stress.

It is also worth noting that for both the OPSC and NWC with strength grade 25 , the splitting tensile to compressive strength ratio was about 0.10; however, for increased compressive strength grade, this ratio was found to decrease. This is in agreement with Tang et al. [24] who reported that the rate of increase in splitting tensile strength was lower compared to the rate of increase in compressive strength for both NWC and LWC and this could be attributed to the increased brittleness of concrete with higher compressive strength.

In this study, it was found that the prediction equation proposed by Shafigh et al. [25] (Eq. (3)) could give fairly accurate estimate of the splitting tensile strength of OPSC with only difference in the range of $5-7 \%$ found between the predicted and experimental splitting tensile strengths. When relating the splitting tensile 
strength to the function of two-third power of the cube compressive strength, the splitting tensile strength prediction equation proposed by Gesoglu et al. [26] (Eq. (4)) for lightweight coldbonded fly ash aggregate concrete with cube compressive strength ranging from 20 to $47 \mathrm{MPa}$ could also be applied for OPSC of this investigation. In this case, the difference in the predicted and experimental splitting tensile strength was about $2-10 \%$. The comparison between the predicted and experimental splitting tensile strengths of OPSC is presented in Fig. 7:

$f_{\mathrm{t}}=0.4887 \sqrt{f}_{\mathrm{cu}}$

$f_{\mathrm{t}}=0.27 f_{\mathrm{cu}}^{2 / 3}$

where $f_{\mathrm{t}}$ is the splitting tensile strength (MPa).

\subsection{Drying shrinkage}

The drying shrinkage process has a significant effect on the cracking of concrete, and therefore is considered to be an important parameter in the design of concrete structures at the serviceability limit. Concrete made with lightweight aggregate is known to experience higher drying shrinkage compared to conventional NWC with differences of up to 50\% reported [27]. Initial research to quantify the shrinkage behaviour of OPSC $[28,29]$ has proved inconclusive due to non-standard nature of the test and comparison methods used. Mannan and Ganapathy [28] adopted long water curing period of specimens during the initial drying period while Abdullah [29] compared the results of OPSC to that of NWC of different strength grades.

Fig. 8 shows the results of drying shrinkage tests for OPSC and NWC of corresponding grades up to the age of 150 days. It has been found that the drying shrinkage of OPSC was in the range of 730850 micro-strains, which was about 2.5 times higher than that of the corresponding NWC (280-350 micro-strains).

It is worth noting that the rate of shrinkage for OPSC and NWC beyond 28 days was found to be similar (Fig. 8). This implies that the main difference in the rate of drying shrinkage lies within the first 28 days of drying period. This is in agreement with McKeen and Ledbetter [30] who reported that the loss of water associated with early age shrinkage was significantly affected by the type of coarse aggregate used; at later ages, however, the effect of coarse aggregates was minimal. Higher shrinkage during the initial drying period is expected as the moisture content of OPS aggregates was higher than that of the granite aggregate due to the porous nature of lightweight aggregate and it is generally accepted that early shrinkage is due to loss of moisture. While shrinkage strains in OPSC are seen to be higher than that of NWC, they are

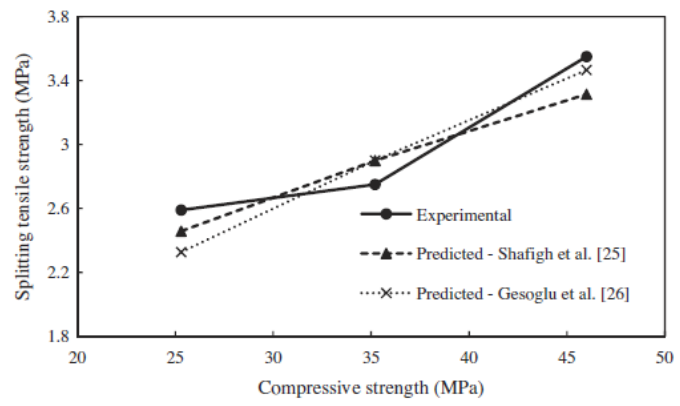

Fig. 7. Experimental and predicted splitting tensile strength of OPSC with different strength grade.

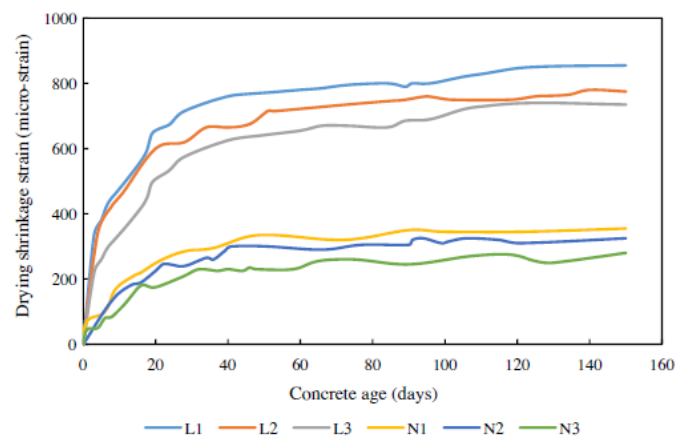

Fig. 8. Drying shrinkage of OPSC and NWC with different strength grade.

generally similar to that seen in other forms of LWC depending on aggregate type [24,31,32].

Another reason for the higher early age shrinkage of OPSC is the lower stiffness of OPS compared to crushed granite aggregate used in NWC. The higher drying shrinkage of concrete prepared with lightweight aggregate, as in the case of OPSC, was likely due to the lower stiffness of the aggregate which provided lower restraining effect on the movement of the cement paste [33,34]. Since the stiffness of aggregate also directly affects the MoE of concrete, the MoE of concrete should theoretically influence the early age drying shrinkage of concrete. Fig. 9 shows that a linear relationship between the drying shrinkage and MoE of both OPSC and NWC exists. Similarly, Alfes [35] also reported a linear relationship between the drying shrinkage of $\mathrm{MoE}$ of high strength concrete.

Furthermore in Fig. 8 it can be seen that drying shrinkage is generally greater for concrete with lower compressive strength, regardless of the type of concrete. This could be attributed to the higher $\mathrm{w} / \mathrm{c}$ ratio and lower cement content in the mixes designed for lower concrete strength. Concrete with higher w/c ratio has higher amount of free water while lower cement content may cause higher volume of capillary pores in the cement matrix; both of these reasons could facilitate water loss from the concrete upon drying and thus lead to greater shrinkage strains in the concrete.

The prediction of the ultimate drying shrinkage of concrete is essential for serviceability and durability design [31]. As the majority of drying shrinkage occurs in the first 28 days, short term tests over this period can be used to develop design equation as shown in the Eq. (5) proposed by Meyers et al. [36]:

$\varepsilon_{\mathrm{t}}=\varepsilon_{\mathrm{ult}} \times[t /(t+N)]$

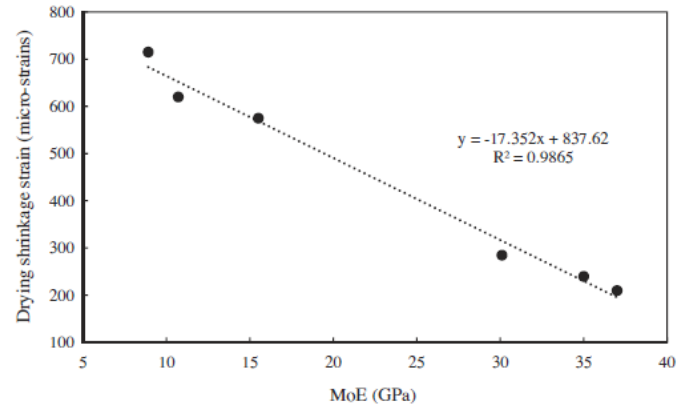

Fig. 9. Relationship between MoE and 28-day drying shrinkage of OPSC and NWC, 
where $\varepsilon_{\mathrm{t}}$ is the shrinkage strain after t days of drying, $\varepsilon_{\text {ult }}$ is the ultimate shrinkage strain and $N$ is an empirical constant taken as 35 .

Using Eq. (5), a comparison between the predicted and measured drying shrinkage of OPSC and NWC is presented in Table 4. When the empirical constant of $N$ is taken as 35 as proposed [36], it was found that the predicted 150-day drying shrinkage strains were approximately $26-34 \%$ higher compared to the measured drying shrinkage strains. Hence, it could be said that the prediction formula may be used for design purpose since it gave overestimation of the drying shrinkage values for safe design. Nevertheless, in order to provide a more accurate estimate of the drying shrinkage strains for both OPSC and NWC, it was suggested to apply modification to Eq. (5) by changing the empirical constant $N$ to 15 . Using this constant, the predicted equation gave a closer estimate of the drying shrinkage values with only difference of $3-15 \%$ as observed in Table 4 . It should be noted, however, that this modified empirical equation is best used for specimens subjected to the drying conditions set out in this investigation. Further research works may be carried out to calibrate the empirical constant with different drying conditions.

\subsection{Bond}

In this study, all the specimens were found to exhibit pull-out failure mode with no splitting cracks observed and this is attributed to the adequate concrete cover provided for the reinforcing bars. Assuming uniform bond stress distribution over the bonded length of concrete, the bond stress $\tau$ for a given slip $\delta$ is given by

$\tau=P /(\pi \times \phi \times L)$

where $P$ is the pull-out load $(N), \phi$ is the diameter of the steel reinforcing bar ( $\mathrm{mm})$ and $L$ is the bond length $(\mathrm{mm})$ which was taken as $3.5 \phi$ in this investigation.

\subsubsection{Bond strength}

The bond stress-slip relationship curves of both OPSC and NWC are shown in Fig. 10. As expected, the increase in the compressive strength of concrete led to increase in the bond strength due to the increased confinement effect on the steel reinforcing bar [37]. The bond strength of OPSC obtained in this investigation was found in the range of 15.9-26.2 MPa, and this was significantly higher compared to the bond strength of OPSC of about $8 \mathrm{MPa}$ reported by previous researchers $[6,7]$. This vast difference in the bond strength was likely due to the splitting cracks observed in the previous research works with insufficient concrete cover that led to premature bond failure of the OPSC

It is interesting to find that for equal compressive strength grade, the bond strength of OPSC were about $50-80 \%$ higher compared to that of NWC. This is in contrary to the finding by Alengaram et al. [7] who reported that the bond strength of

Table 4

Experimental and predicted drying shrinkage strains of OPSC and NWC at 150 days.

\begin{tabular}{|c|c|c|c|c|c|c|}
\hline \multirow[t]{3}{*}{ Mix } & \multicolumn{6}{|c|}{ Drying shrinkage strains (micro-strains) } \\
\hline & \multirow{2}{*}{28 days $^{\exp }$} & \multirow{2}{*}{150 days $^{\exp }$} & \multicolumn{2}{|c|}{ Ultimate $^{\text {pre }}$} & \multicolumn{2}{|l|}{150 days $^{\text {pre }}$} \\
\hline & & & $N=35$ & $N=15$ & $N=35$ & $N=15$ \\
\hline L1 & 715 & 855 & 1609 & 1098 & $1304(0.66)$ & $998(0.85)$ \\
\hline L2 & 620 & 775 & 1395 & 952 & $1131(0.69)$ & $866(0.89)$ \\
\hline L3 & 575 & 735 & 1294 & 883 & $1049(0.70)$ & $803(0.92)$ \\
\hline N1 & 285 & 355 & 641 & 438 & $520(0.68)$ & $398(0.89)$ \\
\hline N2 & 240 & 325 & 540 & 369 & $438(0.74)$ & $335(0.97)$ \\
\hline N3 & 210 & 280 & 473 & 323 & $383(0.73)$ & $293(0.96)$ \\
\hline
\end{tabular}

pre and exp denote predicted and experimental values, respectively; value in parentheses represents ratio of experimental to the predicted drying shrinkage strains.

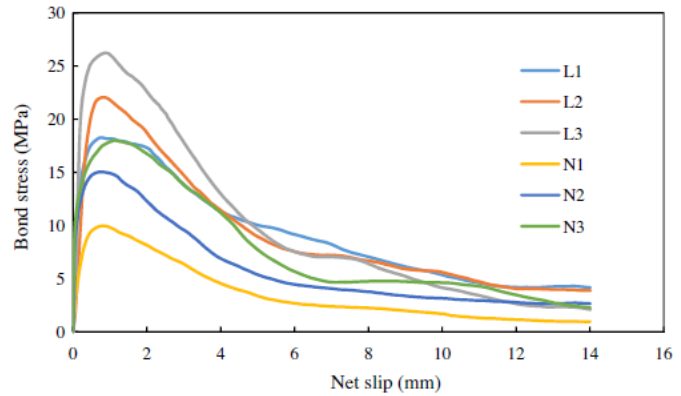

Fig. 10. Bond stress-slip relationship for OPSC and NWC.

OPSC was only about $80 \%$ of that for NWC. As explained earlier, this was due to the splitting failure of pull-out specimens in their study.

Although some researchers also reported higher bond strength of NWC compared to LWC $[11,12,38]$, the results obtained in this study suggested otherwise. This is in agreement with the results of the latest research works carried out on the bond properties of LWC which found higher bond strength of LWC compared to NWC $[15,39]$. One of the possible reasons for the higher bond strength of OPSC is the use of higher cement content in the OPSC mixes compared to the NWC mixes. The higher amount of cement used could enhance the cement paste quality and subsequently improve the interfacial zone [39]. As shown in Fig. 11, a direct relationship exists between the cement content and the bond strength, regardless the type of aggregate. Upon examining the effect of the $w / c$ ratio on the bond strength of concrete, it was found that a more prevailing relationship exists with superior correlation obtained (Fig. 12). This is in agreement with Bogas et al. [39] who reported that the $\mathrm{w} / \mathrm{c}$ ratio having the greatest influence on the bond strength of concrete, regardless the type of aggregate used. The use of lower $\mathrm{w} / \mathrm{c}$ ratio could improve the bond performance of concrete through four ways: improvement in adhesion; increase in concrete crushing strength at the steel reinforcing ba ribs; reduction in shrinkage which could cause internal cracking. lessen bleeding under the reinforcing bar [39]. Choi and Kang [40] also reported an increase in the bond strength for recycled aggregate concrete with lower $\mathrm{w} / \mathrm{c}$ ratio.

Another reason for the superior bond strength for OPSC compared to NWC could be the aggregate interlocking effect of OPS. The aggregate interlock characteristic of OPS aggregate was suggested to be the reason for stronger bonding between OPSC and steel reinforcing bar [41]. Lachemi et al. [11] also reported that

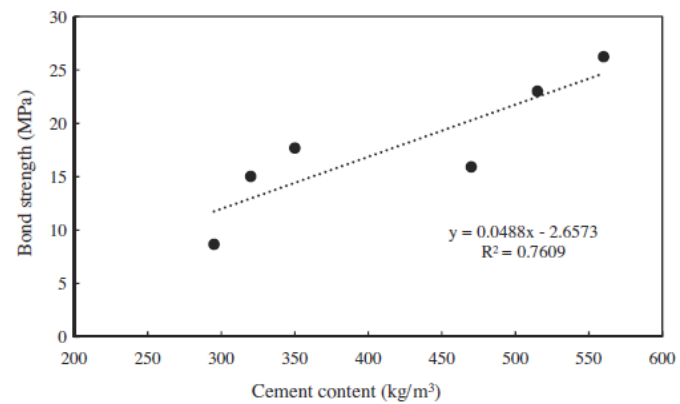

Fig. 11. Effect of cement content on the bond strength of concrete.

Link to Full-Text Articles :

http://www.sciencedirect.com/science/article/pii/S0950061815002871 
http://ac.els-cdn.com/S0950061815002871/1-s2.0-S0950061815002871- main.pdf? tid=565b4374-4010-11e5bd80-00000aab0f01\&acdnat $=1439287641$ 161f50ab14bdc582d74245317c3b5533 